\title{
IMPLICAÇÕES EPISTEMOLÓGICAS E TEÓRICAS DA INCORPORAÇÃO DOS CONCEITOS DE SER MAIS E INCONCLUSÃO NA EDUCAÇÃO AMBIENTAL
}

\author{
Daniel Fonseca de Andrade ${ }^{1}$ \\ Marcelo Senna Guimarães ${ }^{2}$
}

\begin{abstract}
Resumo
O objetivo deste texto é estabelecer a importância da incorporação dos conceitos de ser mais e inconclusão como referenciais para a educação ambiental. Para tal, promovemos o desvelamento conceitual e a contextualização histórica que justifica o resgate desses conceitos e tecemos uma costura entre eles com um enfoque nas suas implicações para a visão de mundo, a organização do socioambiente e da educação ambiental. Como resultado, propomos que tanto o socioambiente quanto o âmbito da educação ambiental sejam vislumbrados a partir das noções de campos contínuos e de um arranjo tridimensional da realidade, que permitam um trânsito livre pelas suas dimensões objetiva, subjetiva e intersubjetiva. Consideramos que esse trânsito, tendo-se em conta a inconclusão e o potencial de ser mais de educadores e educandos, poderá colaborar na construção de processos educadores ambientalistas que, ao terem como meio e fim a afirmação da humanidade dos envolvidos, desafiarão a mentalidade colonizadora predominante e contribuirão para o reencantamento da vida.
\end{abstract}

Palavras-chave: Objetividade, subjetividade e intersubjetividade. Afirmação da humanidade. Tridimensionalidade. Campos contínuos.

\section{THEORETICAL AND EPISTEMOLOGICAL IMPLICATIONS OF THE INCORPORATION OF THE CONCEPTS OF BEING MORE FULLY HUMAN AND INCOMPLETION IN ENVIRONMENTAL EDUCATION}

\begin{abstract}
The objective of this essay is to establish the importance of the incorporation of the concepts of being more fully human and incompletion as references for environmental education. To such an end, we promote their conceptual unveiling and the historical contextualization that justify their incorporation, and shed light to the implications of this incorporation to the worldview, the organization of the socioenvironment and the environmental education field. As outcomes, we propose that both the socioenvironmental and the environmental education fields are seen through the notions of continuous fields and the tridimensional organization of reality, which allow a free flow through its objective, subjective and intersubjective dimensions. We consider that this flow, bearing in mind subjects' incompletion and their possibilities to be more fully human, can collaborate with the construction of environmental education processes which, by having both as means and ends the affirmation of the humanity of those involved, challenge the predominant colonizing mindset and contribute to the re-enchantment of life.
\end{abstract}

Keywords: Objectivity, subjectivity and intersubjectivity. Affirmation of humanity. Tridimensionality. Continuous fields.

\footnotetext{
${ }^{1}$ Doutor em Ciência Ambiental pela Universidade de São Paulo, professor do Departamento de Ciências do Ambiente da UNIRIO. Coordenador do LAPEAr, Laboratório de Ações e Pesquisas em Educação Ambiental. Email: daniel.andrade@unirio.br

${ }^{2}$ Doutor em Educação pela Universidade do Estado do Rio de Janeiro, UERJ e Professor do Departamento de Filosofia da Universidade Federal do Estado do Rio de Janeiro/UNIRIO. E-mail: klynamen@ gmail.com
} 


\section{IMPLICACIONES EPISTEMOLÓGICAS Y TEÓRICAS DE LA INCORPORACIÓN DE LOS CONCEPTOS DE SER MÁS E INCONCLUSIÓN EN LA EDUCACIÓN AMBIENTAL}

\section{Resumen}

El objetivo de este texto es establecer la importancia de la incorporación de los conceptos de ser más e inconclusión como referentes para la educación ambiental. Para ello, promovemos el desvelamiento conceptual y la contextualización histórica que justifica el rescate de esos conceptos y tejemos una costura entre ellos con un enfoque en sus implicaciones para la visión del mundo, la organización del socio-ambiente y de la educación ambiental. Como resultado, proponemos que tanto el socio-ambiente como el campo de la educación ambiental sean vislumbrados a partir de las nociones de campos continuos y de una visión tridimensional de la realidad, que permitan un tránsito libre por sus dimensiones objetiva, subjetiva e intersubjetiva. Consideramos que ese tránsito, teniendo en cuenta la inconclusión de los sujetos y su posibilidad de ser más, puede colaborar en la construcción de procesos de educación ambiental que, al tener como medio y fin la afirmación de la humanidad de los involucrados, desafían la mentalidad colonizadora predominante y contribuyen al reencantamiento de la vida.

Palabras clave: Objetividad, subjetividad e inter-subjetividad. Afirmación de la humanidad. Tridimensionalidad. Campos continuos.

\section{Introdução}

Por isto é que o empenho para a união dos oprimidos não pode ser um trabalho de pura "sloganização" ideológica. É que este, distorcendo a relação autêntica entre o sujeito e a realidade objetiva, divide também o cognoscitivo do afetivo e do ativo que, no fundo, são uma totalidade indicotomizável (FREIRE, 1987).

O objetivo deste texto é estabelecer implicações epistemológicas e teóricas da incorporação dos conceitos de ser mais e inconclusão como referenciais para a educação ambiental (EA). Mais especificamente, o texto sugere tais implicações para a visão de mundo e para as percepções sobre o socioambiente e o campo da EA.

A importância do conceito de ser mais para a educação e para a EA está relacionada à necessidade de consideração, nos processos de ensinoaprendizagem ${ }^{3}$, de educadores e educandos como seres em "permanente movimento de busca" (FREIRE, 1987, p. 30) ou em "processo de construção de si" (TROMBETTA; TROMBETTA, 2010, p. 416), cuja natureza não é "determinada por estruturas ou princípios inatos" (ZITKOSKI, 2010, p. 369). Isso significa que, subjacente às intenções específicas de um processo educativo, ou de uma atividade pedagógica, está esse caminhar constante em direção ao que ainda não somos, um caminhar que é infinito (TROMBETTA; TROMBETTA, 2010).

Para Freire (1987), a busca do ser mais pelo processo de ensinoaprendizagem é uma busca pela humanização dos nele envolvidos, uma busca pela sua libertação, ou ainda sua "afirmação como sujeito" (FREIRE, 2011, p. 62). Nesse sentido, e central neste texto, é o reconhecimento de que a afirmação dessa humanidade requer a percepção de si e do outro na

\footnotetext{
${ }^{3}$ Inspirados por Alves (2008), usamos a terminologia ensinoaprendizagem escrita dessa forma, por considerarmos que esses processos se dão assim, em comunhão, e nunca de maneira oposta ou dicotomizada como nos é ensinado pela ciência moderna.
} 
sua integralidade, a qual compreende as componentes psicológica, psicossocial e gnosiológica (TASSARA; ARDANS, 2005) da vida e dos envolvidos no processo educativo.

Assim, processos educativos que carreguem consigo o papel subjacente de reafirmar a humanidade dos envolvidos não podem ignorar essas componentes e nem esfacelar a totalidade dos nele envolvidos. Como destaca Freire (1998, p. 26), "quando vivemos a autenticidade exigida pela prática de ensinar-aprender participamos de uma experiência total (grifo nosso), diretiva, política, ideológica, gnosiológica, pedagógica, estética e ética”.

O destaque ao conceito de inconclusão é quase intuitivo dentro do contexto delineado acima. Perceber educandos e educadores como seres a serem mais pressupõe, imediatamente, a consideração do seu inacabamento, da sua inconclusão.

De forma mais precisa, considerar homens e mulheres como inconclusos é reconhecer a impossibilidade de seus pensamentos ou discursos encerrarem, em si, a totalidade do objeto ao qual se referem (BOHM, 1995). Em outras palavras, não importa quão profunda e ampla seja uma determinada visão, teoria ou opinião sobre algo, ela jamais será capaz de abarcar esse algo em sua totalidade. Portanto, haverá sempre elementos deixados de fora, e assim novas possibilidades de intepretação e novos caminhos na construção do ser mais.

A ênfase no conceito da inconclusão, assim como o de ser mais, baseia-se na obra de Freire $(1987,1998,2011)$. Para o autor, a noção de inconclusão é essencial para a ocorrência do diálogo no encontro com o outro e, portanto, no processo educativo.

Do ponto de vista epistemológico, a justificativa para a evidenciação do conceito de inconclusão dá-se nas várias críticas que existem quanto aos limites do pensamento ocidental em oferecer princípios adequados para a compreensão da realidade, o que inclui, também, a compreensão de como assimilamos a realidade (MORIN, 1990, 2001; BOHM, 1995; CAPRA, 1997; NICOLESCU, 1999; SANTOS, 2001).

A motivação para se combinar, aqui, os conceitos do ser mais e da inconclusão com as três componentes destacadas por Tassara e Ardans (2005) proveio da elaboração feita por Weber (2005) sobre o processo de racionalização do ocidente, que, segundo interpretação de Habermas (1995), teria se dado por meio da desintegração da unidade do pensamento religioso tradicional em três diferentes dimensões: a subjetiva - componente psicológica de Tassara e Ardans (2005); a intersubjetiva - componente psicossocial de Tassara e Ardans (2005); a objetiva - componente gnosiológica de Tassara e Ardans (2005). Essas dimensões teriam, com o tempo, se estilhaçado em dimensões linguísticas separadas umas das outras, tornando-se autônomas e hierarquizadas, com a primazia da dimensão objetiva em detrimento das demais.

Assim, partimos do pressuposto que esse desmembramento da totalidade do pensamento tradicional em dimensões apartadas traz consequências desumanizadoras, que são perpetuadas por processos de ensinoaprendizagem que, por exemplo, não reconhecem a totalidade de educadores e educandos e que, assim, mantêm o enfoque exclusivo em uma delas. Dessa forma, essa questão precisa ser levada em conta em iniciativas educacionais que possuam como intenção explícita a reafirmação da humanidade de educadores e educandos, considerando-os, portanto, na sua integralidade.

Desse modo, consideramos que esses dois conceitos se colocam, complementarmente, como fundamentais para a construção de ideários pedagógicos da EA, e que demais princípios, objetivos e orientações metodológicas se arranjariam sobre eles.

Este trabalho está organizado em quatro partes. As partes um e dois dedicam-se ao desvelamento conceitual e à contextualização histórica que justificam a ênfase colocada aqui sobre os conceitos de ser mais e inconclusão. A parte 3 promove uma costura entre esses dois conceitos e foca nas implicações epistemológicas e teóricas dessa costura, mais especificamente para a visão de mundo, e para a organização do socioambiente e da educação ambiental. Finalmente, a parte quatro tece considerações finais acerca do assunto tratado. 


\section{A racionalização do ocidente e a importância do ser mais para a educação ambiental}

A contribuição do período histórico chamado de revolução científica para a formatação dos princípios de pensamento que fundamentam a maneira como os ocidentais se veem diante do mundo e da natureza é amplamente reconhecida. Autores como Morin (1990, 2001), Bohm (1995), Capra (1997), Nicolescu (1999), Santos (2001) e Leff (2001, 2006), a partir de diferentes perspectivas, são alguns dos que analisam criticamente as principais características e as implicações socioambientais contemporâneas, dentre outras, decorrentes do pensamento moderno.

O que esses autores abordam é a paulatina construção de uma racionalidade centrada na busca pela verdade indubitável, "clara e distintamente" (DESCARTES, 2001, p. 23) e saneada de qualquer possibilidade de dúvida. Uma das principais características desse pensamento é a fragmentação (CAPRA, 1997). A fragmentação do pensamento é uma forma de organização mental que opera separando a realidade em porções, de forma a se produzirem escopos reduzidos (questões ou problemas com um reduzido número de variáveis), que são assim mais compreensíveis para a mente humana (MORIN, 1990). Nessas porções reduzidas, os nexos de causa e consequência entre as variáveis envolvidas são mais facilmente identificáveis (DESCARTES, 2001), o que permite a emergência da noção de objetividade, e por extensão, de certeza (LEFF, 2006).

Um dos efeitos colaterais dessa forma de organização do pensamento, no entanto, é a percepção de que a fragmentação é não apenas uma operação cognitiva artificial que colabora com a apreensão lógica da realidade, mas a realidade em si, como se ela (a fragmentação) existisse no mundo independente do pensamento (BOHM, 1995). Em outras palavras, é a naturalização da projeção da fragmentação para a realidade observada. Tem-se com isso a noção de que a realidade é e funciona, de fato, da mesma forma fragmentada com que é organizada nos pensamentos. Como coloca Bohm (1995, p. 2, tradução nossa):

[...] quando essa forma de pensamento é aplicada mais amplamente à noção que o homem tem dele mesmo e do mundo inteiro no qual ele vive (ou seja, na sua autovisão de mundo), então o homem para de considerar as divisões resultantes como meramente úteis ou convenientes e começa a ver e experienciar a ele mesmo e seu mundo como de fato constituídos de fragmentos separados.

A consequência disso para o pensamento ocidental é a emergência de uma visão de mundo que compreende a realidade como constituída por partes ou partículas (grifo nosso) elementares independentes que, quando interagem, o fazem apenas externamente, sem que se produzam alterações em suas essências (BOHM, 1995). São como ladrilhos justapostos em uma parede (MORIN, 2007) compondo, assim, um universo percebido como mecânico, em que relações entre seus componentes ocorrem tais quais as engrenagens de máquinas (BOHM, 1995, 1999; CAPRA, 1997).

Seguindo esse raciocínio, ocidentais compreendem o mundo por meio da fragmentação aplicada a si e ao entorno (BOHM, 1995, 1999). Consequentemente, ao agir, projetam essa fragmentação no mundo e a confirmam em seu pensamento, em um processo que se retroalimenta e se autoperpetua indefinidamente, pois "um pensamento mutilador conduz necessariamente a ações mutiladoras" (MORIN, 1990, p.22). Pode-se ainda complementar a visão do autor, reconhecendo que ações mutiladoras produzirão e reforçarão pensamentos mutiladores pré-existentes.

Embora a influência do período da revolução científica para as questões ambientais atuais já tenha sido bastante abordada dentro do universo da EA, por exemplo, por Greig, Pike e Selby (1989), Grün (1996), Medina (1997), Viégas (2005) e Carvalho (2012), além de outros, o foco na fragmentação do pensamento promovida pela emergência da ciência, e suas consequências, apesar de fundamental, não é suficiente. É preciso que se vá além, para uma 
compreensão mais abrangente desse processo histórico, porque ele é complexo e possui implicações sutis para o presente que, até o momento, estão deixadas de fora do campo da EA.

Weber (2005) é outro autor que aborda o processo de racionalização do ocidente. Entretanto, ele o faz por uma perspectiva diferente, que, se não encerra a questão, complementa a dimensão científica colocada acima e oferece novas possibilidades para reflexão. Para o foco deste trabalho, os conceitos de ser mais e inconclusão, suas considerações trazem elementos importantes.

Conforme interpretado por Habermas (1995), Weber associa o período de racionalização do ocidente a um processo de "desencantamento do mundo" (MCCARTHY, 1995, p. xix, tradução nossa), no qual a unidade do pensamento religioso tradicional foi "descentrada" (HABERMAS, 1995, p. 74, tradução nossa) em distintas "esferas culturais de valor" (p. 165, tradução nossa), "ciência e tecnologia, arte e literatura, lei e moralidade" (p. 165, tradução nossa), contendo, respectivamente, os elementos "cognitivos, estético-expressivos e morais-avaliativos" (p. 163, tradução nossa) derivados da condição ontológica primordial.

Portanto, diferentemente dos autores que abordam o período meramente com foco na fragmentação do pensamento promovida pela ciência (e no seu apuramento ao longo do tempo, assim como nas implicações práticas desse apuramento), Weber (2005) fornece uma perspectiva a partir de outro ângulo. Ele explica o processo fazendo referência ao pensamento original e às implicações da sua racionalização (que se daria por meio da paulatina desintegração desse pensamento) para as dimensões que com ela se diferenciam, se estabelecem e se autonomizam, objetiva, subjetiva e intersubjetiva.

Logo, a construção de condições para a emergência da modernidade estaria ligada à formação gradual de uma forma de pensar que separa e individualiza os pensamentos objetivo (ou racional-proposital, associado ao emprego de meios para o alcance de fins), subjetivo (ou afetivo, ligado aos afetos e estados emocionais) e intersubjetivo (ou valor-racional, ligado ao valor intrínseco de certo modo de comportamento - ético, estético ou religioso).

Segundo Habermas (1995), a fragmentação do pensamento ontológico nas três esferas culturais de valor influenciou tanto os conceitos fundamentais com os quais as realidades são interpretadas (as visões de mundo), como também a formação e estabilização das identidades individuais e coletivas. Como ele coloca em seu texto, a "unidade imediata do verdadeiro, do bom e do perfeito, que é sugerida pelos conceitos básicos religiosos e metafísicos, se desfaz" (248-9, tradução nossa). Como consequência, tem-se a "dessocialização da natureza e a desnaturalização da sociedade" (p. 48, tradução nossa), a objetificação dos fatos do mundo, das relações interpessoais e das expressões subjetivas. Como coloca Wilber (1998, p. 40, tradução nossa),

\footnotetext{
Essa dissociação das esferas culturais de valor é exatamente o que começou a acontecer com a arte, a ciência e a moral. Se a diferenciação moderna iniciou seriamente por volta dos séculos dezesseis e dezessete, pelo final do século dezoito e começo do dezenove a diferenciação já estava se tornando uma dissociação dolorosa e patológica. Arte, ciência e moral começaram a ir para caminhos separados, com pouco ou nenhum discurso entre essas esferas, e isso preparou o contexto para uma invasão dramática, triunfante e assustadora das outras esferas por uma ciência explosiva. [...] Colocando de forma direta, o EU e o NÓS foram colonizados pelo ISSO. [...] Os domínios subjetivos e interiores, o EU e o NÓS foram achatados em processos objetivos, exteriores, empíricos, atomísticos ou sistêmicos.
}

Assim, a emergência da era moderna viu a dimensão proposital-utilitarista da racionalidade se sobrepor às ações ligadas à racionalidade dos valores (dimensão intersubjetiva) e da estética (dimensão subjetiva). Para Habermas (1995), esse processo estaria atrelado à priorização da autopreservação e à manutenção das existências individuais, ações empenhadas como uma tarefa "cega, autodirecionada e intransitiva" (p. 388, tradução nossa). 
Com isso, as inter-relações humanas e a subjetividade deixaram de ser intermediadas por valores, normas e compreensão linguística, tornando-se reificadas, implicando na colonização do eu e do nós pelo isso, conforme a concepção de Wilber (1998). O próprio ego teria se transformado em uma espécie de agente dessa razão instrumental, já que ele não só promove a expansão da fronteira utilitarista do mundo externo, como também porque se autocontrola e se autosubjuga, agenciando a sua própria reificação (HABERMAS, 1995).

Como colocam Adorno e Horkheimer (1985), a razão instrumental elegeu a dominação da natureza interna e externa como a finalidade absoluta da vida. Como enfatizam os autores em seu texto,

\begin{abstract}
[n]o instante em que o homem elide a consciência de si como natureza, todos os fins para os quais ele se mantém vivo - o progresso social, o aumento de suas forças materiais e espirituais, até mesmo a própria consciência - tornam-se nulos, [...]. O domínio do homem sobre si mesmo, em que se funda o seu ser, é sempre a destruição virtual do sujeito ao serviço do qual ele ocorre; pois a substância dominada, oprimida e dissolvida pela autoconservação, nada mais é senão o ser vivo, cujas funções configuram, elas tão somente, as atividades da autoconservação, por conseguinte exatamente aquilo que na verdade devia ser conservado (p. 60-61).
\end{abstract}

Como se vê, o processo de racionalização do ocidente deu-se por meio da objetificação do pensamento e do mundo, operação essa que só poderia ocorrer com a demarcação de uma distância insuperável entre aqueles que observam (os sujeitos) e aquilo que é observado (o objeto) (SANTOS, 2001). Como colocam Capra (1997) e Santos (2001), a busca pela verdade absoluta (ou seja, da verdade primordial independente de interpretação) pressupunha a existência de sujeitos neutros (e, portanto, isentos de qualquer influência que pudesse orientar os resultados de suas observações) e de um mundo estático e sem história, cujas verdades seriam extraídas por esses sujeitos.

Wilber (1998), acima, demonstrou como o processo de objetificação da realidade ocorrido durante a racionalização do ocidente significou, também, um processo de colonização dessa mesma realidade. Objetificar significa transformar em objeto, e para tal qualquer essência existente, qualquer sacralidade, precisa ser extraída. A partir daí, esse objeto torna-se apropriável e manipulável. Por outro lado, esse objeto, para ser, precisa do sujeito (o observador) que o determine. Está aí demarcada a base mental para a colonização.

Quijano (1992) aborda essa questão em seu texto, demonstrando o modo pelo qual a mentalidade colonizadora, propulsionada pelo capitalismo europeu, foi o etos da expansão europeia a partir do século $\mathrm{XV}$, e se estabeleceu como paradigma também nas terras conquistadas, colocando-se como forma de pensar absoluta, como se não houvesse sequer a possibilidade de visões de mundo alternativas. $\mathrm{O}$ autor discute, da mesma forma, como que o valor de objeto foi importante para que terras, povos e culturas estivessem disponíveis à conquista, ao extermínio e à subjugação.

Olhando-se para essa questão a partir do século XXI, percebe-se como a mentalidade colonizadora, que pressupõe um sujeito independente e um objeto (e, portanto, destituído de qualquer essência), de fato colonizou as culturas e as mentes da grande maioria dos territórios conquistados, por meio da simples aniquilação, da ameaça ou da sedução (QUIJANO, 1992).

Exemplos das implicações práticas dessa forma de pensamento são encontrados em todos os lugares, desde o tratamento dado pelo estado brasileiro à natureza (e as justificativas recorrentes para a sua degradação), aos povos que não se encerram no ideal global consumistaurbano-branco-cristão-classe-média (indígenas, quilombolas, ribeirinhos, agricultores, caiçaras, pobres, negros etc.) e até, como ressaltaram Adorno e Horkheimer (1985) acima, ao tratamento dado pelos ocidentais aos seus próprios corpos e suas próprias vidas. Em todos esses exemplos, e vários outros, predominam a visão do outro (natureza, humano não global e corpos) como coisa, vazio, destituído de essência, apenas forma e sem conteúdo, a ser também colonizado, manipulado, possuído, transformado e controlado. Como não poderia deixar de ser, 
tal relação se instalou e predomina até os dias atuais também na educação, naquela tradição que se tornou reconhecida mundialmente como educação bancária (FREIRE, 1987).

Portanto, o processo de desmembramento do pensamento tradicional nas três esferas culturais de valor ocorrido ao longo da racionalização do ocidente construiu, também, as bases de um pensamento no qual o outro, seja ele o que ou quem for, será obrigatoriamente percebido como um objeto. Concernente à natureza, essa forma de pensar e agir conduz a sua progressiva redução à condição de recurso natural, à disposição do mercado. Concernente aos homens, mulheres e sociedades, conduz à desumanização. Nada mais adequado ao pensamento capitalista, que está constante e ferozmente em busca de "novos pastos" dos quais se alimentar (BAUMAN, 2010, p. 27).

É dentro desse contexto que os conceitos propostos aqui se inscrevem. Diante da contínua redução do outro à mera condição de coisa ou de "mercadoria" (BAUMAN, 2008, p. 13) propomos, como fundamento de reflexão e de práticas de ensinoaprendizagem, a ênfase no ser mais de educadores e educandos.

Para Zitkoski (2010, p. 370), o ser mais está ligado à percepção da vida enquanto "processo aberto", que é construído e reconstruído à medida que um indivíduo faz a sua própria história. Ser mais está, assim, ligado à historicização da vida, a um processo de libertação de um "hoje permanente" (FREIRE, 2011, p. 57) do qual "não tem consciência" (FREIRE, 2011, p. 57) para o atingimento do ontem, o reconhecimento do hoje e o descobrimento do amanhã. Com isso, o indivíduo torna-se sujeito de sua própria história, e ao fazer essa história, se faz (TROMBETTA; TROMBETTA, 2010).

Neste texto, o destaque dado ao conceito de ser mais no processo de ensinoaprendizagem atenta, mais especificamente, à importância do reconhecimento de homens e mulheres aprendentes na sua totalidade, a totalidade objetivo-subjetivo-intersubjetivo. Em outras palavras, à afirmação de sua humanidade. Como a EA se configura (ao menos em intenção) como um campo interdisciplinar e multidimensional (FÓRUM...1992; BRASIL, 1999, 2014), consideramos que ela é um lugar privilegiado para tal, já que pode transitar organicamente por essas dimensões sem ficar refém da mutilação cartesiana e nem da necessidade permanente de objetificação da realidade e dos sujeitos nela contidos.

$\mathrm{Na}$ prática, entretanto, enfatizar o ser mais como referencial para a EA significa considerar que as questões socioambientais que justificam e animam as suas práticas pedagógicas, por princípio, podem ser abordadas a partir de qualquer uma das três dimensões da realidade (técnico-científica, subjetiva ou intersubjetiva). O fundamental, no entanto, é que não se perca de vista que no momento de um enfoque específico, questões importantes para o ensinoaprendizagem daquela determinada questão e aos anseios do ser mais (presentes nas demais dimensões) estarão sendo deixadas de fora.

Elas poderão, todavia, ser naturalmente trazidas ao processo por meio do acesso as outras dimensões um pouco mais à frente nas práticas. Assim, como educadores, se olharmos para as questões socioambientais do mundo mantendo como referência a totalidade dos sujeitos envolvidos, reconheceremos que, para a EA, não há dimensão exclusiva que instigue o seu fazer, tampouco uma origem disciplinar. Há enfoques e há escolhas, mas que devem ser localizadas dentro dessa totalidade maior, infinita. Como coloca Freire (1987, p. 96), "a questão fundamental, neste caso, está em que, faltando aos homens uma compreensão crítica da totalidade em que estão, captando-a em pedaços nos quais não reconhecem a interação constituinte da mesma totalidade, não podem conhecê-la".

Portanto, reconhece-se, aqui, que a realidade não se inscreve exclusiva e nem predominantemente em uma ou outra dimensão, como se estivessem apartadas por fronteiras intransponíveis, mas compõe um amálgama fluido com elas, em constante interação. Essa percepção favorece a organicidade do tratamento de questões e uma maior possibilidade afirmação da humanidade dos envolvidos, navegando-se entre dimensões à medida que o 
momento demande, sem cerceamentos por um ou outro enfoque considerado de forma absoluta como mais relevante.

Assim, o princípio do cuidado com o ser mais de educadores e educandos em relação, e o esforço para a consideração do outro a partir da ética da outridade (LEFF, 2006) oferecem alguns caminhos à transcendência da mentalidade colonizadora que fundamentou a construção e que reproduz a realidade socioambiental encontrada no planeta atualmente.

Obviamente, esse comprometimento com totalidade objetivo-subjetivo-intersubjetivo vai conduzir à percepção de que nenhuma prática, nenhum pensamento, nenhum conceito, nenhuma abordagem e nenhuma teoria é capaz de trazer, em si, a completude. Isso deve estimular, nas interações educadoras, a compreensão da necessidade constante e epistêmica da busca, do ser mais (FREIRE, 1987). Por ser a inconclusão uma questão tão elementar dentro desse processo, ela é o segundo conceito fundamental a ser enfatizado.

\section{Sobre a inconclusão}

O repertório teórico da formação do pensamento moderno também justifica a inclusão, aqui, do conceito da inconclusão. Foi visto acima que uma das consequências da organização fragmentada do pensamento é a naturalização da sua projeção para o mundo, ou seja, é a percepção de que a realidade é e funciona da mesma forma fragmentada como está organizada nos pensamentos ocidentais. Outra consequência dessa visão, que deriva da primeira, mas que é sutilmente diferente, é a noção que a operação da fragmentação propicia, de se tomar a parte pelo todo. Dito de outra forma, é a noção que convence homens e mulheres de que a parte da realidade à qual têm acesso constitui, de fato, a totalidade daquilo que existe. Com isso, naturaliza-se o pressuposto de que apenas uma visão de mundo, ou ponto de vista, é capaz de abranger essa totalidade, em todas as suas dimensões e escalas, e permite-se construção da ideia de que é possível que se extraia dela a certeza absoluta (MORIN, 2001).

A noção de inconclusão se constrói sobre princípios que são diferentes. Aqui, assumimos que pensamentos não correspondem à realidade, mas são traduções e interpretações (MORIN, 2007) a seu respeito, a partir de uma noção subjacente de ordem pré-estabelecida (um paradigma), de conceitos teóricos já existentes (BOHM, 1995), de interesses, motivações e do conhecimento disponível em um determinado momento (BOHM, 1999). Não somos, assim, sujeitos-decodificadores, "perseguindo leis imutáveis, reais, permanentes e inequívocas", mas sujeitos-intérpretes "diante de um mundo-texto", na busca de produção de sentidos dentro de um horizonte histórico (CARVALHO, 2012, p. 83).

Consequentemente, consideramos que a realidade possui muito mais em si do que jamais será concebido pelo pensamento (MORIN, 1990), de forma que sempre uma porção dela continuará implícita e intangível, com significados atribuídos sempre limitados. É o que coloca Bohm (1999, p. 81, tradução nossa), “[o] que uma pessoa percebe não é a coisa em si, que é desconhecida e desconhecível, mas aquilo que ela significa naquele momento". Nesse contexto, a realidade está, também, sempre aberta a novos desvelamentos e novas interpretações (CARVALHO, 2012).

Além disso, se a realidade não é acessível plenamente ao pensamento, a capacidade de descrição daquilo que foi compreendido é ainda menor. Como Bohm (1999, p.80, tradução nossa) enfatiza, somos capazes de compreender apenas tacitamente grande parte de nossas existências: "qualquer coisa que dizemos ou fazemos, nós não podemos possivelmente descrever em detalhes mais do que uma pequena parte do significado total que percebemos em um determinado momento". Portanto, limitados àquilo que foi compreendido em um determinado momento, podemos responder a certas questões feitas à realidade, e não à totalidade das questões (MORIN, 2001). 
Do ponto de vista pedagógico, o reconhecimento da inconclusão é fundamental. Quando a realidade é tratada a partir da noção de certeza (seja uma certeza epistemológica, isto é, de que os princípios sobre os quais uma verdade qualquer foi construída são válidos, seja dos conteúdos construídos sobre esses princípios - a verdade em si), a consequência, quase lógica, disso é a redução de educandos e educandas à condição de recipientes passivos dessa verdade desistoricizada, pronta e acabada, sobre um mundo também pronto e acabado.

Isso estabelece a relação assimétrica educador-educando descrita por Freire (1987, p.59) que, como ele mesmo afirma, se configura como uma forma de opressão. Opressão porque determina um papel, aos educandos, de espectadores do mundo e da vida, inclusive das suas próprias. Opressão porque tolhe a elaboração mental, a expressão, a criatividade, a reflexão, a iniciativa, a fantasia e, enfim, a autoridade. Como o autor coloca, é opressão porque envolve educandos e educandas como "meros objetos", o que se configura, no fim das contas, como uma forma de colonização.

Neste contexto, entendemos que um dos papéis da EA é colocar educadores e educandos em contato com a sua própria inconclusão e, ao mesmo tempo, propiciar-lhes as condições para que acessem o "caráter histórico e da historicidade dos homens". Dessa forma, perceberão a impossibilidade de considerar suas histórias como determinadas, imobilizadas ou cristalizadas. Pelo contrário, serão convidados a se ver como "seres que estão sendo [...] em e com uma realidade" que é também inacabada (FREIRE, 1987, p. 72). Em outras palavras, ao acolher educandos como sujeitos, educadores e educadoras devem se esforçar (apesar do peso histórico da tradição pedagógica) em estimular que os mesmos produzam e re-produzam suas próprias narrativas sobre si e sobre o mundo, e, com isso, exercitem a percepção de si como alguém que está sendo e que faz. Freire (1987, p.30) esclarece em seu trabalho que a busca pelo ser mais é uma "luta pela humanização, pelo trabalho livre, pela desalienação, pela afirmação dos homens como pessoas, como "seres para sí". No fim, entendemos que esse deva ser também o objetivo maior da EA.

\section{Costurando as noções de ser mais e inconclusão: implicações para a visão de mundo}

Como começou a ser perceptível acima, a incorporação dos conceitos de ser mais e inconclusão no campo da EA traz implicações muito mais amplas do que para a simples esfera conceitual em si. Ela toca, também, na visão de mundo e, por consequência, na noção sobre a organização do socioambiente e do campo da EA. Esta seção do texto versa sobre essas questões, com a finalidade de alinhar de forma coesa a epistemologia e a teoria que animam o ideário de EA proposto aqui.

Como visto acima, nosso olhar sobre a EA parte de um desafio tanto da noção de fragmentação (do pensamento e da realidade) quanto da possibilidade da certeza. Isso não significa a refutação completa dessas duas noções, como se não colaborassem, de forma alguma, com a compreensão da realidade e o desenvolvimento do pensamento, mas o reconhecimento de que elas são válidas e adequadas a contextos limitados (BOHM, 1995).

$\mathrm{Na}$ visão de mundo que estamos entalhando neste texto, a realidade é percebida (e organizada) de forma diferente, não como constituída por partículas independentes e autônomas, ou corpos rígidos e indivisíveis, apartados uns dos outros por fronteiras bem delimitadas e intransponíveis, mas a partir da noção de campos (BOHM, 1995). Nessa noção, o que se compreende como as partes individuais no olhar ocidental, são apenas regiões de intensa concentração de um campo maior, de forma que essas partes se conectam a outras, também áreas de intensa concentração, por meio de espaços mais difusos.

Tais campos são, desse modo, percebidos como contínuos e em movimento, sempre com uma história, um devir. Consequentemente, o que é reconhecido no arranjo ocidental de pensamento como uma singularidade autônoma e separada das demais, pura, é considerada 
apenas uma área mais concentrada de um campo, que é contínuo e que se torna menos concentrado à medida que se distancia dessa singularidade, até se misturar novamente a outros campos mais concentrados (outras singularidades na visão tradicional) (BOHM, 1995).

Assim, essa noção não concebe a fragmentação, que isola e torna independente, mas a existência de uma "totalidade indivisa" (BOHM, 1995, p. 11, tradução nossa). Não admite, consequentemente, a possibilidade da pureza, mas o caráter contraditório da realidade (MORIN, 2001). Da mesma forma, não concebe a cristalização do mundo, já que compreende a realidade como em movimento fluido e orgânico.

Bohm (1995, p.149, tradução nossa) denomina essa noção de ordem na qual as coisas não podem ser consideradas a partir da fragmentação, mas relacionadas por um campo fluido e vivo que as atravessa e une, como ordem "implicada", que se refere ao fluxo subjacente que conecta implicitamente aquilo que é explicitamente considerado como isolado, separado, autônomo e independente pela visão de mundo ocidental, a qual é chamada pelo autor de "ordem explicada". Dito de outra forma, o que a ordem ocidental concebe como partícula independente é visto apenas como uma emergência visível que se manifesta de um fluxo subjacente contínuo invisível, a "totalidade indivisa" mencionada por Bohm (1995, p.11, tradução nossa). Obviamente, por uma questão de inteligibilidade, essa ordem explicada pode ser simplificada por meio da sua redução à singularização, mas os limites dessa operação não podem ser ignorados. Como coloca Isaacs (1999, p. 34, tradução nossa), "dividir as coisas não é o problema. E, sim, esquecer a conexão".

A manifestação, no mundo e na vida, dessa organização de pensamento que considera a realidade em fluxo pode ser ilustrada de várias maneiras. Por exemplo, se fizermos uma análise do que o pensamento ocidental considera como um indivíduo humano, palavra que carrega consigo uma noção de independência, veremos que muito pouco dele é, de fato, individual: seu corpo material é formado a partir de um fluxo de matéria subjacente que ele adquiriu e adquire por meio da alimentação, matéria essa que já constituiu vários outros corpos biológicos ao longo da história, possivelmente de organismos de todos os reinos existentes, além, também, de já ter feito parte do planeta físico.

Todos os dias, em pequenas quantidades, e após a sua morte, essa matéria segue o seu curso pelo percurso biológico-mineral; seus genes não são seus, mas provenientes de uma cascata genética histórica, cujo percurso é muito difícil de rastrear para além de algumas gerações, mas que conecta povos, etnias, culturas e tempos; a energia que move o pulsar de seu coração, seu corpo como um todo e suas elaborações mentais chegou até a si proveniente do sol, mas sofreu várias escalas por outros seres vivos ao longo de todo o processo. Assim como a matéria, essa energia não para aí, mas continua o seu fluxo a todo instante em que ela é emanada pelo indivíduo; o conhecimento que o indivíduo detém também não é dele, mas chegou a ele por meio de coisas que ouviu, presenciou, leu, sentiu etc. Nesse contexto, as únicas coisas mais individuais são as misturas que o indivíduo produz e o rumo que dá a elas, que, por sua vez, entrarão nesse fluxo e farão parte das vidas de outros indivíduos.

Esse é apenas um exemplo, a partir da ideia de individualidade de um humano, do papel dos fluxos da realidade conectando e constituindo essas próprias realidades. Também, demonstra como a compreensão do funcionamento da realidade em fluxos produz percepções diferentes sobre essa mesma realidade em comparação com o que seria se ela fosse olhada a partir da fragmentação. Pelo exemplo acima, o fluxo nos coloca, humanos, diante da arbitrariedade cultural das fronteiras que nos separam da natureza e do resto da humanidade.

Outros exemplos podem ainda ser trazidos, como a ideia da bomba biótica produzida pela transpiração das árvores da Floresta Amazônica, que resgata para o continente a umidade oceânica que é responsável pela irrigação de uma boa porção da América do Sul (NOBRE, 2014); dos salmões nas árvores (DRAKE; NAIMAN; BECHTOLD, 2006), que demonstra como o nitrogênio contido nos corpos dos salmões que morrem ao desovar nas cabeceiras das 
corredeiras em florestas do hemisfério norte vai parar, ao longo de um caminho pela teia alimentar, nos tecidos das árvores da floresta circundante; ou ainda, da descoberta de que a mudança drástica na população de lobos de uma região nos EUA acabou por levar à alteração do curso de um rio no local (BESCHTA; RIPPLE, 2006).

Todos esses e ainda vários outros processos que poderiam ser explicitados, demonstram que a realidade não comporta fragmentações e que, portanto, tudo o que existe está, de alguma forma, conectado temporal e espacialmente, em algum nível (BOHM, 1999). Fica, assim, explícita a consequência artificializadora, desnaturalizadora e desumanizadora da fragmentação.

Nesse contexto, assumindo-se, portanto, o cunho unitário e irredutível do socioambiente, entendemos que as abordagens multidimensionais e multirreferenciais (ARDOINO, 2001) sejam enquadramentos mais adequados para sua análise e compreensão. Por permitirem o trânsito por diferentes dimensões das questões postas (objetiva, subjetiva e intersubjetiva), e a partir de diferentes perspectivas, demarcam o seu caráter interdisciplinar (o encontro entre diferentes campos do saber acadêmico) e transdisciplinar (que inclui nesse cenário, também, saberes provenientes de outras experiências de vida, de culturas e de epistemologias) (OLIVEIRA, 2005). Nesse referencial, a EA assume uma aptidão muito forte para ser vista como um campo com uma tendência pós-normal (FUNTOWICZ; RAVETZ, 2000) de ciência, ou seja, que é realizada por meio (e que, ao fazê-lo, fomenta) da ecologia de saberes (SANTOS, 2002) ou o diálogo de saberes (LEFF, 2006).

\subsection{Costurando as noções de ser mais e inconclusão: implicações para a organização do socioambiente e o campo da EA}

A noção de campos, demonstrada acima como configuração de uma visão de mundo, traz implicações quando empregada nas ideias que fazemos da organização do socioambiente e também da área da EA. Carvalho (1998, p. 114) já fez esse exercício, e como consequência descreveu o socioambiente como um "campo contraditório e diversificado de discursos e valores [...]", sem "fronteiras e formas precisas". Nessa descrição, ela usa a terminologia proposta por Alphandéry, Bitoun e Dupont (1992, apud CARVALHO, 1998, p.114), que caracterizam o campo socioambiental como uma "nebulosa". Para o presente trabalho, a ideia de nebulosa é muito pertinente, já que carrega consigo as noções de difusão e movimento constante do e no campo, entendimentos que queremos promover por meio da ideia de campos. Assim, nos apropriamos dessa noção e a estendemos também à visão que fazemos da EA.

Como resultado, propomos uma visão do campo da EA que seja organizada para além do arranjo mono ou bidimensional, normalmente atribuído a ela. No caso, o arranjo monodimensional seria aquele no qual a EA é vista como um ponto neutro no espaço, desistoricizada e desterritorializada, manifestada na prática como as propostas pedagógicas que são feitas para qualquer realidade independentemente de condições e contextos específicos postos. Nesses casos, o socioambiente é um enorme vazio e a única coisa que importa é a prática em si.

Como arranjo bidimensional compreendemos aquele no qual o socioambiente e o campo da EA são reduzidos ou a uma linearidade, que obrigatoriamente opõe e hierarquiza os seus constituintes (SANTOS, 2002), ou a um plano, que os distribui em uma superfície (como em bifurcações), e que acaba, também, por organizá-los por meio da linearidade, como visto, por exemplo, em Fien (1993) e Pepper, (1997). Não se deseja, aqui, com o exposto acima, desqualificar a importância, principalmente histórica, dessas e outras tipologias para a compreensão dos campos ambiental e da EA, apenas reconhecer que elas também carregam consigo limites que precisam ser explicitados, primeiro para que não sejam tomadas de forma 
literal, e segundo para que não condicionem por demais as análises interpretativas que serão realizadas no futuro.

$\mathrm{Na}$ noção sugerida neste trabalho, a realidade é espacial, configurada em uma tridimensionalidade (objetivo-subjetivo-intersubjetivo) viva e dinâmica, historicizada, na qual os diferentes componentes do campo da EA, como as concentrações no campo de Bohm (1995), aproximam-se, mesclam-se e distanciam-se ao longo do tempo ou em função de questões específicas (temas, enfoques, abordagens etc.). Dessa forma, carregamos conosco os sentidos atribuídos ao campo pela nebulosa, porém arranjamos esses sentidos em um ambiente que é explicitamente tridimensional e indiviso.

Assim, ao consideramos o socioambiente e o campo da EA como emergências de um fluxo, possibilitamos a sua conexão a outros campos (que são olhares provenientes de outras áreas do saber, de outras culturas etc.) com os quais eles dinamicamente se integram e se dissociam (configurando, dessa forma, o seu caráter inter e transdisciplinar). Portanto, o que temos como resultado é uma organização de pensamento que se esforça em dissolver as fronteiras entre as dimensões objetiva, subjetiva e intersubjetiva da vida, e em permitir que o fluxo se dê naturalmente entre elas. Dito de outra forma, que de uma determinada dimensão (a objetiva, por exemplo), possam emergir questões próprias das outras (subjetiva ou intersubjetiva), hologramaticamente (MORIN, 2001, p.190), pois partir dessa visão "o todo está na parte que está no todo".

Assim, questões objetivas da realidade não precisam ser olhadas apenas objetivamente, já que carregam consigo elementos potencialmente subjetivos e intersubjetivos. Com isso, transcendemos a monocultura do pensamento, respeitamos a totalidade de educadores e educandos e trazemos para o processo de ensinoaprendizagem uma maior possibilidade de fomento do ser mais.

Para ilustrar o que foi dito acima, vamos considerar o que deve ser a questão mais comum de ser tratada por projetos de EA: a questão do lixo. O lixo pode ser visto a partir de uma perspectiva exclusivamente objetiva, o que se manifesta na prática como as abordagens técnicas: caracterização dos materiais, tempo de decomposição, formas de reciclagem etc. Alguns projetos de EA se limitam exclusivamente a práticas do tipo, o que pode ser considerado como uma forma de reducionismo (ANDRADE; SORRENTINO, 2013).

A partir da visão hologramática da realidade, entretanto, uma prática a partir do lixo carrega também, em si, o potencial para transitar pelas demais dimensões, por exemplo, incluindo-se nelas discussões sobre a desigualdade social, a injustiça ambiental e a lógica do capitalismo (o que estaria inscrito na dimensão intersubjetiva), e também relativas à autoestima, à identidade e ao autovalor (inscritos na dimensão subjetiva). Ou seja, a partir do referencial colocado neste trabalho, da realidade em fluxo, do ser mais e da inconclusão, as práticas que limitam seu enfoque a apenas uma das dimensões acabam por reproduzir a desumanização dos envolvidos, justamente por deixarem não atendidas questões fundamentais à totalidade e, portanto, à busca do ser mais.

Da mesma forma, poderemos trazer para essa conversa saberes de outros tempos, povos e culturas, aproximando o campo da EA a outros não acadêmicos. Com isso, estaremos mais próximos de atender às demandas de educadores e educandos na sua totalidade, exercitaremos o diálogo de saberes e levaremos em consideração a inconclusão das práticas. É a vontade de preencher essa inconclusão que leva ao desejo de ser mais. Importante, nesse processo, no entanto, é que a prática seja capaz de se localizar dentro da questão socioambiental maior na qual se insere e se questionar sobre o seu papel dentro dessa questão.

Por fim, para serem coerentes, práticas pedagógicas que carregam esse pano de fundo interdisciplinar, transdisciplinar e multidimensional precisam ser orientadas por outros 
princípios e objetivos ${ }^{4}$ também interdisciplinares, transdisciplinares e multidimensionais. Assim, a partir da análise de referenciais da EA (FÓRUM..., 1992, BRASIL, 1999, 2005), da nossa experiência de vida e também fruto de diálogos com nossos estudantes e outros educadores, reconhecemos como objetivos possíveis para práticas de $\mathrm{EA}^{5}$ : o fomento do pensamento crítico/reflexivo/questionador (considerado aqui como a capacidade de se atribuir sentidos e significados outros a versões hegemônicas sobre a realidade); do pensamento integrado, baseado na realidade em fluxos; da proatividade; da autoestima; da criatividade; da solidariedade e da cooperação; da potência do agir individual e coletiva; da historicização de si, da vida e do mundo; do diálogo orgânico entre teoria-prática-teoria; do encantamento com a vida, as culturas, a natureza e a diversidade; do otimismo; da esperança; da formação, resgate e fortalecimento de identidades individuais e coletivas; da capacidade de aprender; da curiosidade epistêmica; do diálogo; do cuidado e do autocuidado; do senso ético, estético e de justiça; da sobrevivência; da empatia; da participação política; da autonomia e da afetividade.

Como pode ser percebido, são objetivos e princípios que se estendem nas dimensões objetiva, subjetiva e intersubjetiva da vida. Mais do que isso, são objetivos e princípios que se relacionam de uma forma que transcende a mera complementaridade cartesiana, como se uns se arranjassem ao lado dos outros (como se fossem independentes uns dos outros e fossem alcançados em isolamento pelos processos educativos) na busca de se ocupar uma maior superfície possível. Também, não podem ser arranjados em categorias mutiladoras, que restringem o processo educativo ou à dimensão objetiva, ou à subjetiva, ou à intersubjetiva. Diferentemente, são considerados como hologramáticos (MORIN, 2001), de forma que de qualquer um deles (princípio ou objetivo) possa emergir outro ou outros, que, por sua vez, se desdobrarão em ainda outros em um sucessivo que pode ser levado ao infinito, em um fluxo que transita livremente, por meio da práxis, pelas três esferas da realidade, à medida que o processo educativo se desenrola.

\section{Considerações Finais}

Neste texto, estabelecemos a importância da incorporação dos conceitos de ser mais e inconclusão na construção de referenciais pedagógicos para a EA, e explicitamos as implicações da incorporação desses conceitos para a visão de mundo, as percepções sobre o socioambiente e o campo da EA. Como visto, a pertinência do destaque atribuído a esses dois conceitos se dá, em primeiro lugar, por reafirmar o lugar de educadores e educandos, na sua totalidade objetiva-subjetiva-intersubjetiva, como a razão de ser do processo educativo ambientalista, e em segundo lugar, por inseri-los como atores em um mundo vivo, em constante construção, e, portanto, incerto e inacabado.

Nesse contexto, e na busca de criarmos coesão entre a epistemologia e a teoria, propusemos a noção de campos como forma de organização da realidade, e da sua configuração tridimensional como meio para a incorporação da realidade a partir da totalidade fluida objetiva-subjetiva-intersubjetiva. Esse arranjo tridimensional fluido objetivo-subjetivointersubjetivo é considerado como fundamental para que o campo da EA, que possui a intenção manifesta de ser inter e transdisciplinar, não fique aprisionado na armadilha epistemológica de se autoanalisar, se auto-organizar e analisar o mundo no passado, no presente e no futuro utilizando-se dos mesmos princípios disciplinares (mono e bidimensionais) que os campos inter e transdisciplinares do pensamento se propõem a transcender.

\footnotetext{
${ }^{4}$ A indissociabilidade entre princípios e objetivos visa enfatizar a busca de coerência entre os fins que são estipulados e os meios pedagógicos através dos quais esses fins são buscados.

${ }^{5}$ Não se pretende, aqui, o oferecimento de uma lista completa e definitiva de objetivos e princípios, mas daqueles que fazem sentido nesse determinado momento.
} 
Isso não significa negar o papel que os modelos, principalmente os bidimensionais, tiveram e têm na história da EA como organizadores do campo (e nem a importância da organização polarizada do pensamento para a própria construção do pensamento), mas ponderar sobre os limites que as visões e organizações polarizadoras trazem para os processos de ensinoaprendizagem, e sugerir que é possível ir além.

Assim, considerando-se a realidade tridimensional em fluxo, reconhecemos que práticas pedagógicas podem transitar pelas dimensões objetiva, subjetiva e intersubjetiva da realidade e também por campos (do conhecimento) de uma maneira livre e orgânica, à medida que a prática pedagógica e os anseios dos envolvidos por ser mais demande, sem os constrangimentos postos por arranjos mentais disciplinares que fragmentam o mundo e que, ao fazerem, acabam por tornar questões (e educadores e educandos) reféns de uma dimensão, de uma área do conhecimento ou ainda de um paradigma.

Por fim, consideramos que esse trânsito pela tridimensionalidade da realidade e por seus diferentes campos, levando-se em consideração a inconclusão e a possibilidade de educadores e educandos de serem mais, pode colaborar na construção de processos educadores ambientalistas que ao terem como meio e fim a afirmação da humanidade dos envolvidos, desafiarão a mentalidade colonizadora predominante e contribuirão para o reencantamento da vida.

\section{Referências}

ADORNO, T.W.; HORKHEIMER, M. Dialética do esclarecimento: fragmentos filosóficos. Rio de Janeiro: Jorge Zahar, 1985.

ALVES, N. Nós somos o que contamos: a narrativa de si como prática de formação. In: SOUZA, E.C.de; MIGNOT, A.C.V. (Orgs). Histórias de vida de formação de professores. Rio de Janeiro: Quartet/Faperj, 2008. p. 131-145.

ANDRADE, D. F. de; SORRENTINO, M. Da gestão ambiental à educação ambiental: as dimensões subjetiva e intersubjetiva nas práticas de educação ambiental. Pesquisa em Educação Ambiental, Rio Claro, v. 8, n.1, p. 88-98, jan-jun. 2013.

ARDOINO, J. A complexidade. In: MORIN, E. A religação dos saberes: o desafio do século XXI. Rio de Janeiro: Bertrand Brasil, 2001. p. 548-558.

BAUMAN, Z. Vida para consumo: a transformação das pessoas em mercadoria. Rio de Janeiro: Zahar, 2008.

BAUMAN, Z. Vida a crédito: conversas com Citlali Rovirosa-Madrazo. Rio de Janeiro: Zahar, 2010.

BESCHTA, R. L.; RIPPLE, W.J. River channel dynamics following extirpation of wolves in northwestern Yellowstone National Park, USA. Earth Surf. Process. Landforms, v.31, n. 14, p. 15251539, Dec. 2006.

BOHM, D. Wholeness and the implicate order. London and New York: Routledge, 1995.

BOHM, D. Unfolding meaning: a weekend of dialogue. London and New York: Routledge, 1999.

BRASIL. Lei n. 9.795 de 27 de abril de 1999. Dispõe sobre a educação ambiental, institui a Política Nacional de Educação Ambiental e dá outras providências. Diário Oficial da União, Brasília, 28 abr. 1999. Seção 1, p.1. 
BRASIL. Programa Nacional de Educação Ambiental. Ministério do Meio Ambiente. Departamento de Educação Ambiental; Ministério da Educação, Coordenação Geral da Educação Ambiental. 3. ed. Brasília: MMA, 2005.

BRASIL. Educação Ambiental: Por um Brasil sustentável. Documentos de Referência para o Fortalecimento da Política e do Programa Nacional de Educação Ambiental, ProNEA, Marcos Legais \& Normativos. Brasília: MMA/MEC, 2014.

CAPRA, F. O ponto de mutação: a ciência, a sociedade e a cultura emergente. 22 ed. São Paulo: Cultrix, 1997.

CARVALHO, I. C. de M. As transformações na cultura e o debate ecológico: desafios políticos para a educação ambiental. In: NOAL, F.O. et al. (Orgs.). Tendências da Educação Ambiental Brasileira. Santa Cruz do Sul: Edunisc, 1998. p. 113-126.

CARVALHO, I. C. de M. Educação ambiental: a formação do sujeito ecológico. 6 ed. São Paulo: Cortez, 2012.

DESCARTES, R. O discurso do método. São Paulo: Martins Fontes, 2001.

DRAKE, D.C.; NAIMAN, R.J.; BECHTOLD, J.S. Fate of Nitrogen in riparian forest soils and trees: an $15 \mathrm{~N}$ tracer study simulating salmon decay. Ecology, Washington, v. 87, n.5, p. 1256-1266, may. 2006.

FIEN, J. Education for the environment: critical curriculum theorising and environmental education. Geelong: Deakin University, 1993.

FÓRUM INTERNACIONAL DE ORGANIZAÇÕES NÃO GOVERNAMENTAIS E MOVIMENTOS SOCIAIS. Tratado das ONGs. Rio de Janeiro, 1992. p. 198- 201.

FREIRE, P. Pedagogia do oprimido. 17 ed. (23 reimpressões). Rio de Janeiro: Paz e Terra, 1987.

FREIRE, P. Pedagogia da autonomia: saberes necessários à prática educativa. 8 ed. São Paulo / Rio de Janeiro: Paz e Terra, 1998.

FREIRE, P. Educação como prática da liberdade. 14 ed. São Paulo: Paz e Terra, 2011.

FUNTOWICZ, S.O.; RAVETZ, J.R. La ciencia posnormal: ciencia con la gente. Barcelona: Icaria \& Antrazyt, 2000.

GREIG, S.; PIKE, G.; SELBY, D. Greenprints for changing schools. London: WWF/Kogan Page, 1989.

GRÜN, M. Ética e educação ambiental: a conexão necessária. 2 ed. Campinas: Papirus, 1996.

HABERMAS, J. The theory of communicative action: reason and the rationalization of society. Vol.1. Cambridge: Polity/Blackwell, 2 reprint, 1995.

ISAACS, W. Dialogue and the art of thinking together: a pioneering approach to communicating in business and in life. New York: Doubleday, 1999.

LEFF, E. Saber ambiental: sustentabilidade, complexidade e poder. Petrópolis: Vozes, 2001.

LEFF, E. Racionalidade ambiental: a reapropriação social da natureza. Rio de Janeiro: Civilização Brasileira, 2006. 
MCCARTHY, T. Translator's introduction. In: HABERMAS, J. The theory of communicative action: reason and the rationalization of society. Vol.1. Cambridge: Polity/Blackwell, 2 reprint, 1995. p. vii xxxix.

MEDINA, N. M. Breve Histórico da Educação Ambiental. In: Pádua, S.M.; Tabanez, M. F. (Orgs.). Educação Ambiental: caminhos trilhados no Brasil. Brasília: IPE, 1997. p. 257 - 269

MORIN, E. Introdução ao pensamento complexo. 2 ed. Lisboa: Instituto Piaget, 1990.

MORIN, E. Ciência com consciência. 5 ed. Rio de Janeiro: Bertrand Brasil, 2001.

MORIN, E. La epistemología de la complejidad. In: GARRIDO, F.; MOLINA, M.G.de.; SERRANO, J.L.; SOLANA, J.L. (Eds.). El paradigma ecológico en las ciencias sociales. Barcelona: Icaria, 2007. p. 55-81.

NICOLESCU, B. O manifesto da transdisciplinaridade. São Paulo: Triom, 1999.

NOBRE, A.D. O Futuro Climático da Amazônia: Relatório de Avaliação Científica. Articulación Regional Amazónica, São José dos Campos, 2014. 42p.

OLIVEIRA, H.T. de. Transdisciplinaridade. In: FERRARO-JÚNIOR, L.A. (Org). Encontros $e$ caminhos: formação de educadoras(es) ambientais e coletivos educadores. Brasília: MMA/DEA, 2005. p. 335-343.

PEPPER, D. Modern Environmentalism: an introduction. London/New York: Routledge, 1997.

QUIJANO, A. Colonialidad y modernidad/racionalidad. Perú Indíg., Lima, v.13, n.29, p. 11-20, 1992.

SANTOS, B. de. S. A crítica da razão indolente: contra o desperdício da experiência. 3 ed. São Paulo: Cortez, 2001.

SANTOS, B. de. S. Para uma sociologia das ausências e uma sociologia das Emergências. Revista crítica de ciências sociais, Coimbra, n.63, p. 237-280, out. 2002.

TASSARA, E.T. de O.; ARDANS, O. Intervenção psicossocial: desvendando o sujeito histórico e desvelando os fundamentos da educação ambiental critica. In: FERRARO JÚNIOR, L. A. (Org.). Encontros e caminhos: formação de educadoras(es) ambientais e coletivos educadores. Brasília: MMA/DEA, 2005. p. 203-216.

TROMBETTA, S.; TROMBETTA, L.C. Vocação ontológica. In: STRECK, D.R.; REDIN, E.; ZITKOSKI, J.J (Orgs.). Dicionário Paulo Freire. 2 Ed. Belo Horizonte: Autêntica, 2010. p. 416-417.

VIÉGAS, A. Complexidade: uma palavra com muitos sentidos. In: FERRARO JÚNIOR, L.A. (Org.). Encontros e caminhos: formação de educadoras(es) ambientais e coletivos educadores. Brasília: MMA/DEA, 2005, p. 73-81.

WEBER, M. The Protestant Ethic and the Spirit of Capitalism. London / New York: Routledge, 2005.

WILBER, K. The marriage of sense and soul: integrating science and religion. New York: Random House, 1998.

ZITKOSKI, J.J. Ser mais. In: STRECK, D.R.; REDIN, E.; ZITKOSKI, J.J (Orgs). Dicionário Paulo Freire. 2 Ed. Belo Horizonte: Autêntica, 2010. p. 369-371. 